\title{
Synergistic airway gland mucus secretion in response to vasoactive intestinal peptide and carbachol is lost in cystic fibrosis
}

\author{
Jae Young Choi, ${ }^{1,2}$ Nam Soo Joo, ${ }^{1}$ Mauri E. Krouse, ${ }^{1}$ Jin V. Wu, ${ }^{1}$ Robert C. Robbins, ${ }^{3}$ \\ Juan P. Ianowski, ${ }^{4}$ John W. Hanrahan, ${ }^{4}$ and Jeffrey J. Wine ${ }^{1}$ \\ ${ }^{1}$ Cystic Fibrosis Research Laboratory, Stanford University, Stanford, California, USA. 2Department of Otorhinolaryngology, Yonsei University, Seoul, \\ Republic of Korea. ${ }^{3}$ Department of Cardiothoracic Surgery, Stanford University, Stanford, California, USA. \\ ${ }^{4}$ Department of Physiology, McGill University, Montreal, Quebec, Canada.
}

\begin{abstract}
Cystic fibrosis (CF) is caused by dysfunction of the CF transmembrane conductance regulator (CFTR), an anion channel whose dysfunction leads to chronic bacterial and fungal airway infections via a pathophysiological cascade that is incompletely understood. Airway glands, which produce most airway mucus, do so in response to both acetylcholine (ACh) and vasoactive intestinal peptide (VIP). CF glands fail to secrete mucus in response to VIP, but do so in response to $\mathrm{ACh}$. Because vagal cholinergic pathways still elicit strong gland mucus secretion in CF subjects, it is unclear whether VIP-stimulated, CFTR-dependent gland secretion participates in innate defense. It was recently hypothesized that airway intrinsic neurons, which express abundant VIP and ACh, are normally active and stimulate low-level gland mucus secretion that is a component of innate mucosal defenses. Here we show that low levels of VIP and ACh produced significant mucus secretion in human glands via strong synergistic interactions; synergy was lost in glands of CF patients. VIP/ACh synergy also existed in pig glands, where it was CFTR dependent, mediated by both $\mathrm{Cl}^{-}$and $\mathrm{HCO}_{3}^{-}$, and clotrimazole sensitive. Loss of "housekeeping" gland mucus secretion in CF, in combination with demonstrated defects in surface epithelia, may play a role in the vulnerability of CF airways to bacterial infections.
\end{abstract}

\section{Introduction}

The recessive genetic disease cystic fibrosis (CF) is caused by the dysfunction of CF transmembrane conductance regulator (CFTR), an anion channel that is activated by pathways that elevate cAMP. In some epithelia, such as intestine $(1,2)$, pancreatic ducts $(3,4)$, and airway submucosal glands (5), CFTR mediates $\mathrm{Cl}^{-}$- or $\mathrm{HCO}_{3}^{-}$dependent fluid secretion, and the loss of CFTR causes reduced fluid secretion in those organs. The most serious clinical problem in CF is lung damage caused by chronic bacterial airway infections. The bacteria in CF airways reside in the mucus, which in normal airways is sterile and mobile (6), suggesting that CF mucus is abnormal both in its ability to be cleared from the airways (7) and in its antimicrobial properties (8). Most airway mucus is thought to arise from submucosal glands $(9,10)$, and in the only direct comparisons ever made of airways with and without glands, airways with glands secreted much more lysozyme and were more resistant to bacterial infections, even though no central innervation of the glands was present $(11,12)$. We hypothesize that abnormalities in airway gland mucus, secondary to loss of CFTR-mediated anion secretion, is a significant contributor to airways pathology in CF (13).

In humans and pigs, airway submucosal glands secrete mucus in response to both acetylcholine (ACh) and vasoactive intestinal peptide (VIP) $(5,14)$. CF glands no longer secrete mucus in response to VIP (5), but do respond to carbachol (15). The nonhydrolyzable ACh analog carbachol produces maximal mucus secre-

Nonstandard abbreviations used: ACh, acetylcholine; CF, cystic fibrosis; CFTR, CF transmembrane conductance regulator; 1-EBIO, 1-ethyl-benzimidazolinone; NKCC, $\mathrm{Na}^{+}, \mathrm{K}^{+}, 2 \mathrm{Cl}^{-}$cotransporter; VIP, vasoactive intestinal peptide.

Conflict of interest: The authors have declared that no conflict of interest exists. Citation for this article: J. Clin. Invest. 117:3118-3127 (2007). doi:10.1172/JCI31992 tion rates (to $10 \mu \mathrm{M}$ ) that are about 2- to 3 -fold greater than those caused by maximal VIP, and most studies of glands use maximal levels of cholinergic stimulation $(10,14)$. However, such stimuli are probably rarely experienced except in acute crises. Instead, mundane pathogens and irritants encountered continuously during normal breathing are more likely to produce low levels of stimulation via both neural and non-neural pathways. The complex innervation of airway glands includes neurons intrinsic to the airways and employs multiple neurotransmitters, sometimes localized in the same neurons (16-21). These facts, in addition to the ability of centrally denervated airways in lung transplant patients to resist chronic infections and the presence of CFTRdependent local pathways in mouse airways (22), have led to a renewed interest in the local neural control of airway glands (23) and argue that the consequences of low-level stimulation by mixed agonists, which probably more closely approximate physiological conditions, need to be evaluated, particularly with reference to gland function in CF (see Discussion).

To our knowledge, the consequences of combinations of lowlevel agonists on secretion of airway gland mucus have not previously been studied. The concentration of agonists that glands experience during normal breathing is not known, but airway vagal efferents display tonic activity during breathing (24), suggesting a resting level of neural excitation of glands. Therefore, in order to determine whether any interactions exist among low levels of agonists, here we used optical methods to measure mucus secretion rates from single glands in situ (25) in response to VIP and carbachol, especially at nanomolar concentrations that might be expected to mimic routine physiological input to the glands. We demonstrated strong synergistic interactions between cholinergic and noncholinergic pathways in humans; importantly, 

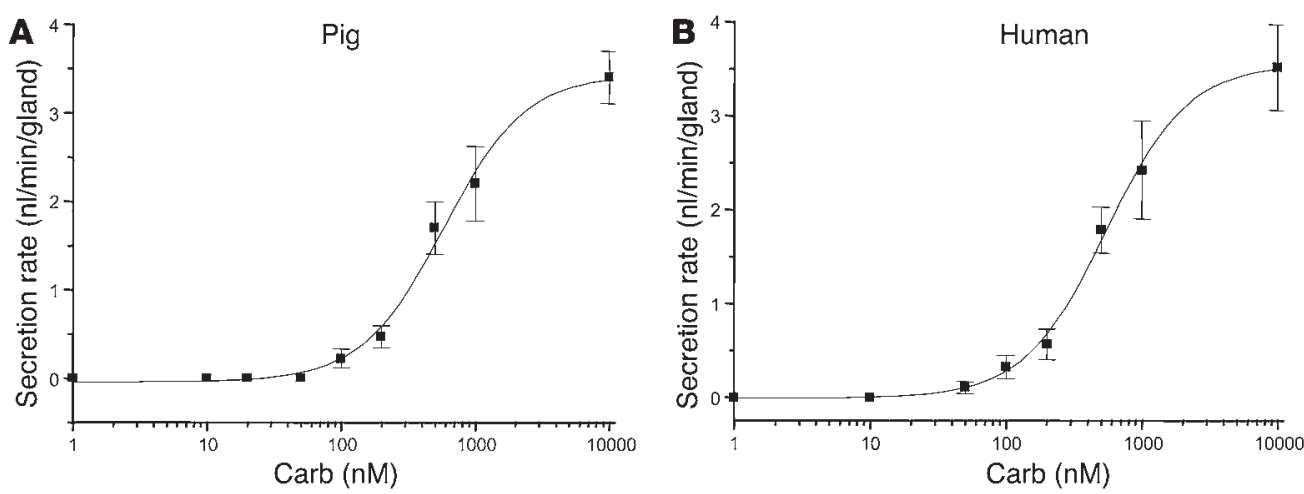

Figure 1

Dose-response relations for airway gland mucus secretion. Shown are pig ( $\mathbf{A}$ and $\mathbf{C}$ ) and human (B and $\mathbf{D}$ ) responses to carbachol (Carb; $\mathbf{A}$ and $\mathbf{B})$ and VIP (C and $\mathbf{D})$. Each point is the result of measurements of 21-43 glands in 4 pigs or 3-4 humans. $V_{\max }$ values were as follows (in $\mathrm{nl} /$ $\mathrm{min} /$ gland): carbachol-exposed pig, $3.43 \pm 0.29$; carbacholexposed human, $3.55 \pm 0.11$; VIP-exposed pig, $1.58 \pm 0.18$; VIP-exposed human, $1.54 \pm 0.09$.
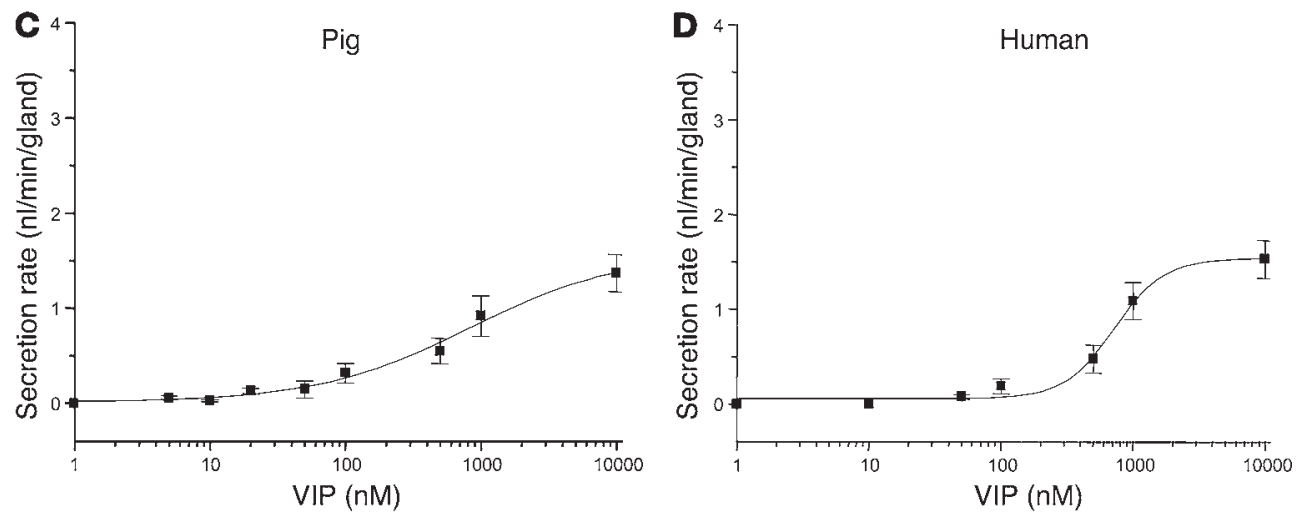
EC50 values were as follows (in $\mathrm{nM})$ : carbachol-exposed pig, $590 \pm 16$; carbachol-exposed human, $545 \pm 42$; VIP-exposed pig, $834 \pm 311$; VIP-exposed human, $717 \pm 76$.

we found that those interactions were lost in human CF glands. We also demonstrated and analyzed VIP-carbachol synergy in pig submucosal glands. Some of these results have been reported in preliminary form in abstracts (26-28).

\section{Results}

Dose-response relations for single gland mucus secretion in buman and pig airway glands. To begin the analysis of interactions between low levels of agonists, we first established dose-response relations for carbachol and VIP in non-CF human bronchi and tracheae and in pig tracheae, using optical methods to determine the rate of mucus secretion from single glands. As shown in Figure 1, pigs and humans had very similar dose-response relations for both agonists. For pigs the threshold (defined as the concentration which produced an obvious increase in mucus secretion rates for at least 2 glands in the optical field) for carbachol stimulation of gland mucus secretion was approximately $100 \mathrm{nM}$, the $\mathrm{EC}_{50}$ was $590 \pm 16 \mathrm{nM}$, and the approximate $V_{\max }$ achieved with $10 \mu \mathrm{M}$ carbachol was $3.43 \pm 0.29 \mathrm{nl} / \mathrm{min} /$ gland $(n=4,27-43$ glands; Figure 1A). For humans, the threshold for carbachol stimulation of gland secretion was approximately $50 \mathrm{nM}$, the $\mathrm{EC}_{50}$ was $545 \pm 42$ $\mathrm{nM}$, and the approximate $V_{\max }$ was $3.51 \pm 0.33 \mathrm{nl} / \mathrm{min} /$ gland $(n=3,21$ glands; Figure 1B). The threshold for VIP in pigs was approximately $20 \mathrm{nM}$, the $\mathrm{EC}_{50}$ was $834 \pm 311 \mathrm{nM}$, and the extrapolated $V_{\max }$ (not achieved with the maximal concentration of 10 $\mu \mathrm{M}$ VIP) was $1.58 \pm 0.18 \mathrm{nl} / \mathrm{min} /$ gland $(n=4,25-36$ glands; Figure $1 \mathrm{C})$. The threshold for VIP in humans was approximately $50 \mathrm{nM}$, the $\mathrm{EC}_{50}$ was $717 \pm 76 \mathrm{nM}$, and maximal stimulation (probably less than $V_{\max }$ and achieved with $10 \mu \mathrm{M}$ VIP) was $1.54 \pm 0.09 \mathrm{nl} /$ min/gland ( $n=4,24$ glands; Figure 1D).

Human glands show synergistic secretory responses to VIP and carbachol. We used the dose-response relations to select concentrations for testing synergistic effects among VIP and carbachol. For human airway glands, subthreshold concentrations of VIP $(10 \mathrm{nM})$ and carbachol $(10 \mathrm{nM})$ produced significant mucus secretion when combined (Figure 2). Images of mucus bubbles under oil just before and 30 minutes after the combined stimulation are shown in Figure 2A. A plot of mucus volume versus time for 10 individual glands from a single subject is shown in Figure 2B, and summary data for 138 airway glands from 16 human subjects are shown in Figure 3. Essentially identical results were obtained for tracheal glands obtained from 9 donor tissues and from bronchial glands obtained from 7 controls with disease other than CF. Human glands secreted mucus in response to the combined stimuli at an average rate of $0.30 \pm 0.18 \mathrm{nl} / \mathrm{min} /$ gland. This was a significant increase $(P<0.001)$ over secretion in response to either agent alone and was approximately $20 \%$ of $V_{\max }$ to VIP and $10 \%$ of $V_{\max }$ to $10 \mu \mathrm{M}$ carbachol. In terms of concentrations, the mucus secretion produced by $10 \mathrm{nM}$ VIP combined with $10 \mathrm{nM}$ carbachol was approximately what would be expected with either $100 \mathrm{nM}$ carbachol or 400 nM VIP alone. In 2 experiments with a single human subject with chronic obstructive pulmonary disease (disease control), 8 glands were followed for longer periods to determine whether there were delayed responses to $10 \mathrm{nM}$ VIP or carbachol alone, and 13 glands were followed for 40-50 minutes with VIP and 1 hour with carbachol before applying the combined stimuli. No increase in mucus secretion was observed during these more prolonged periods, but rapid increases in secretion occurred to the combined stimuli for 10 of 13 glands (data not shown).

CF glands lack a synergistic secretory response to VIP and carbachol. Previous work showed that glands from subjects with CF are refractory to stimulation with VIP or forskolin, although they still respond to carbachol (5). To determine whether synergy between VIP and carbachol was also affected in subjects with CF, we applied 
A
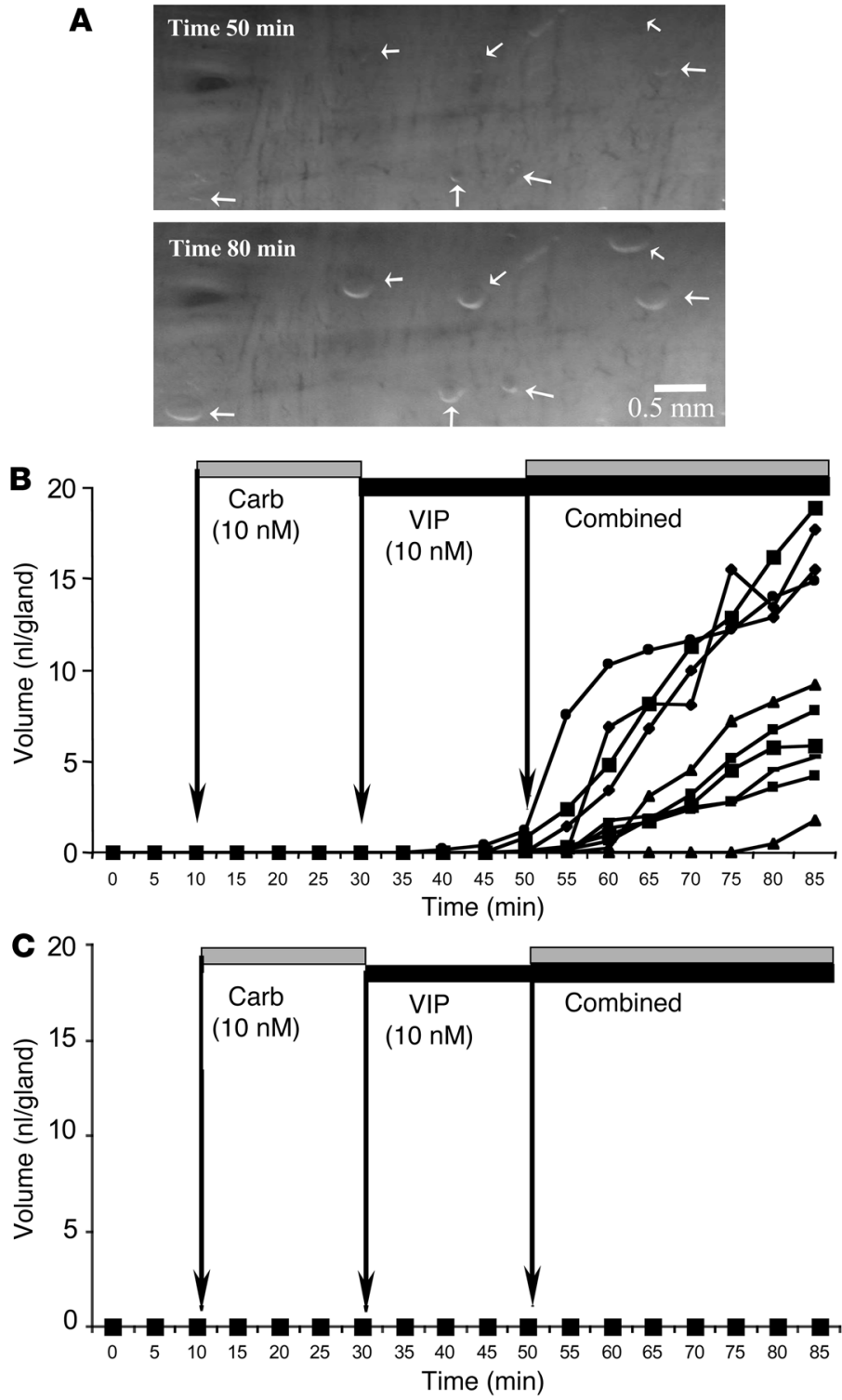

the same paradigm that produced synergy in human control tissues to CF tissues. In marked contrast with controls, we found that CF glands failed to respond to the combination of carbachol and VIP that was efficacious in controls (Figure $2 \mathrm{C}$ and Figure 3 ). The mean response was essentially $0(0.002 \pm 0.008 \mathrm{nl} / \mathrm{min} ; n=7,71$ glands) and did not differ significantly from the response to either agent alone. However, the CF glands were viable because they still responded vigorously to $1 \mu \mathrm{M}$ carbachol, which produced mucus secretion of $3.10 \pm 1.13 \mathrm{nl} / \mathrm{min} /$ gland (Figure 3, inset).

Synergistic stimulation of mucus secretion by VIP and carbachol in pig airway glands. Because pig airway tissues are consistently available, we sought to determine whether pig glands displayed a similar form of synergy so that we could use pigs to begin analyzing the mechanisms of synergy. We found that pig tracheal glands, like human glands, showed marked synergy between subthreshold concentrations of VIP and carbachol (Figure 4). A single experiment recording 7 responding glands is shown in Figure $4 \mathrm{~A}$, and the mean mucus secretion rate for each condition $(n=4$,

\section{Figure 2}

Synergistic stimulation of human airway gland mucus secretion by carbachol in combination with VIP. (A) Raw data of the type used for analysis; 7 glands from a donor trachea supplied part of the data plotted in B. Each image shows the same airway region after being cleaned and oiled (see Methods). Mucus secretion from individual glands formed spherical bubbles in the oil, whose volume was measured optically. The top image was taken 40 minutes after sequential exposure to $10 \mathrm{nM}$ carbachol and VIP (20 minutes each) and the bottom image after 30 minutes exposure to the combined agonists. Arrows show corresponding gland openings. Exposure to $20 \mathrm{nM}$ of either agonist was ineffective (see Figure 1). Scale bar: $0.5 \mathrm{~mm}$. (B) Plot of mucus volume versus time for 10 single glands stimulated sequentially with $10 \mathrm{nM}$ carbachol, $10 \mathrm{nM} \mathrm{VIP}$, and the combination. The tissue was washed for 1 minute with Krebs-Ringer buffer after carbachol. (C) Plot of 10 bronchial glands from a single patient with CF stimulated with the identical protocol as the donor trachea. Unlike donor glands, no synergy occurred, but when the carbachol concentration was increased 100 -fold to $1 \mu \mathrm{M}$, the CF glands secreted mucus vigorously, indicating that they were still viable (not shown).

34 glands) is shown in Figure 4B. The response in the combined condition was significantly increased versus either condition alone, producing a mean mucus secretion rate of $0.33 \pm 0.11 \mathrm{nl} / \mathrm{min} /$ gland $(P<0.01)$. Atropine $(1 \mu \mathrm{M})$ had no effect on mucus secretion produced by suprathreshold levels of VIP used alone (data not shown), but, as expected, it abolished synergy between low levels of carbachol and VIP $(n=3,19$ glands; $P<0.05)$.

We next determined the interactions of VIP and carbachol over a range of agonist concentrations $(n=5,9-36$ glands, per condition). We first tested a 1,000-fold range of VIP concentrations ( $1 \mathrm{nM}$ to $10 \mu \mathrm{M})$ either alone or with the addition of 20 or $50 \mathrm{nM}$ carbachol, which are subthreshold when used alone in pigs. As shown in Figure 5A, either concentration of carbachol markedly increased mucus secretion for all VIP concentrations of $10 \mathrm{nM}$ or greater. We then held the VIP concentration constant at $10 \mathrm{nM}$ and added increasing concentrations of carbachol $(1 \mathrm{nM}$ to $10 \mu \mathrm{M})$. As shown in Figure 5B, synergy (and indeed additivity) was lost at carbachol concentrations greater than $100 \mathrm{nM}$, after which there was complete occlusion ( $n=4,7-45$ glands, per condition). The dose response to carbachol alone was well fitted with a single sigmoid $(P<0.001)$, but the combination of VIP and carbachol was best fit with 2 sigmoids (the double sigmoid was better than a single sigmoid; $P<0.025$ ), suggesting a second process was operating at lower concentrations.

Synergy dependent on CAMP and CFTR. To begin the analysis of the mechanisms responsible for synergy between carbachol and VIP, we first asked whether forskolin, which bypasses VIP receptors and directly activates adenylate cyclase, can substitute for VIP in the synergy paradigm. When combined with $20 \mathrm{nM}$ carbachol, 100 $\mathrm{nM}$ forskolin (a subthreshold concentration for pig and human gland mucus secretion when used alone; data not shown), produced in pigs a mucus secretion rate of $0.26 \pm 0.08 \mathrm{nl} / \mathrm{min} /$ gland (Figure 4C), similar to the synergy produced by VIP (Figure 4B). Forskolin was also tested in experiments with 2 humans using $100 \mathrm{nM}$ forskolin alone or in combination with $10 \mathrm{nM}$ carbachol. Of 10 glands tested, none responded to either agent alone, but 8 of 10 glands secreted mucus in response to the combination 


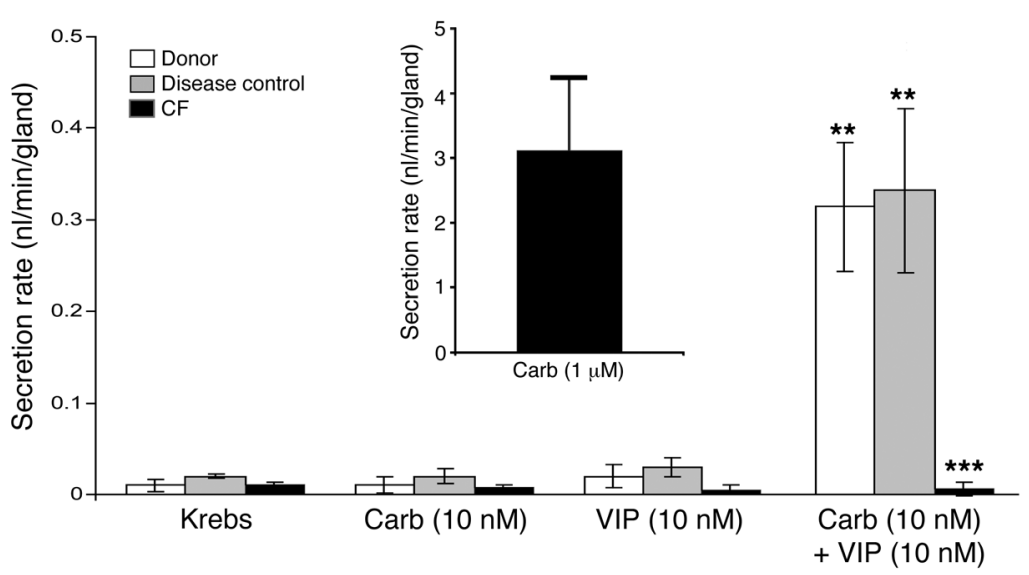

\section{Figure 3}

Summary data comparing synergistic stimulation of mucus secretion in human control glands with the lack of synergy in CF glands. Data was obtained from 9 donor tracheae (72 glands), bronchi from 7 disease controls (66 glands), and bronchi from 7 patients with CF (71 glands). For each control group, the combined treatments produced significantly greater mucus secretion than did either treatment alone, but CF subjects did not respond to the combined treatment, and the difference between $\mathrm{CF}$ and either control group was significant. ${ }^{\star \star} P<0.01 ;{ }^{* *} P<0.001$. Inset: CF glands were still viable, as determined by their robust secretion in response to a 100 -fold higher concentration of carbachol. (data not shown). Thus, forskolin could substitute for VIP to produce synergy with carbachol. This is of interest because a previous report of VIP-ACh synergy for glyconjugate release by cat glands found that db-cAMP could not substitute for VIP (29). This point is addressed again in Discussion.

Fluid secretion by pig airway glands is driven by anion secretion (10, 30-34), and the lack of synergy in tissues from humans with CF indicated that synergy in humans requires CFTR. We next sought to determine the relative contributions of CFTR and $\mathrm{Ca}^{2+}$-activated chloride channels to the synergistic effect in pig glands. For this purpose, we stimulated mucus secretion with 20 $\mathrm{nM}$ carbachol plus $10 \mathrm{nM}$ VIP, which gave a mucus secretion rate of $0.29 \pm 0.09 \mathrm{nl} / \mathrm{min} /$ gland, and then added either $40 \mu \mathrm{M}$ niflumic acid to inhibit $\mathrm{Ca}^{2+}$-activated chloride channels (35) or $20 \mu \mathrm{M}$
CFTR $_{\text {inh-172 }}$ to inhibit CFTR channels (36) (Figure 6A). The synergistic response was not inhibited by $40 \mu \mathrm{M}$ niflumic acid (mucus secretion rate, $0.27 \pm 0.12 \mathrm{nl} / \mathrm{min} /$ gland; NS). In contrast, $20 \mu \mathrm{M}$ CFTR $_{\text {inh }}-172$ reduced the response significantly (mucus secretion rate, $0.08 \pm 0.01 \mathrm{nl} / \mathrm{min} /$ gland; $P<0.01$ ). Inhibition with $\mathrm{CFTR}_{\text {inh }^{-}}$ 172 was consistent with the lack of synergy in humans who lacked functional CFTR, as shown in Figure 2C and Figure 3. The lack of inhibition by niflumic acid could mean that $\mathrm{Ca}^{2+}$-activated chloride channels are not activated by low levels of carbachol, but before making this conclusion, we needed a positive control for the effects of niflumic acid on gland mucus secretion.

Role of $\mathrm{Ca}^{2+}$-activated $\mathrm{Cl}^{-}$channels. Mucus secretion by glands becomes at least partially independent of CFTR at higher concentrations of carbachol (refs. 5, 15, 22, 26, 37-40, and Figure 3,
Figure 4

Pig airway glands also show synergy between VIP and carbachol stimulation of mucus secretion. (A) An example of 7 tracheal glands from a single pig trachea stimulated with 20 $\mathrm{nM}$ carbachol, $10 \mathrm{nM}$ VIP, and the combination. As in humans, synergy was observed with the combined treatment; a slightly higher carbachol concentration was used with pigs. (B) Summary data for 34 glands from 4 pigs. The response to combined agonists was significantly greater than either agonist used alone. The synergistic response was blocked by atropine (19 glands in 3 pigs). (C) Summary data for forskolin (Fors) and carbachol stimulation of mucus secretion for 18 glands from 3 pigs demonstrated that forskolin can substitute for VIP to produce synergy with carbachol. Note that $100 \mathrm{nM}$ forskolin was required to see synergy equivalent to $10 \mathrm{nM}$ VIP. ${ }^{*} P<0.05 ;{ }^{* *} P<0.01$.
A
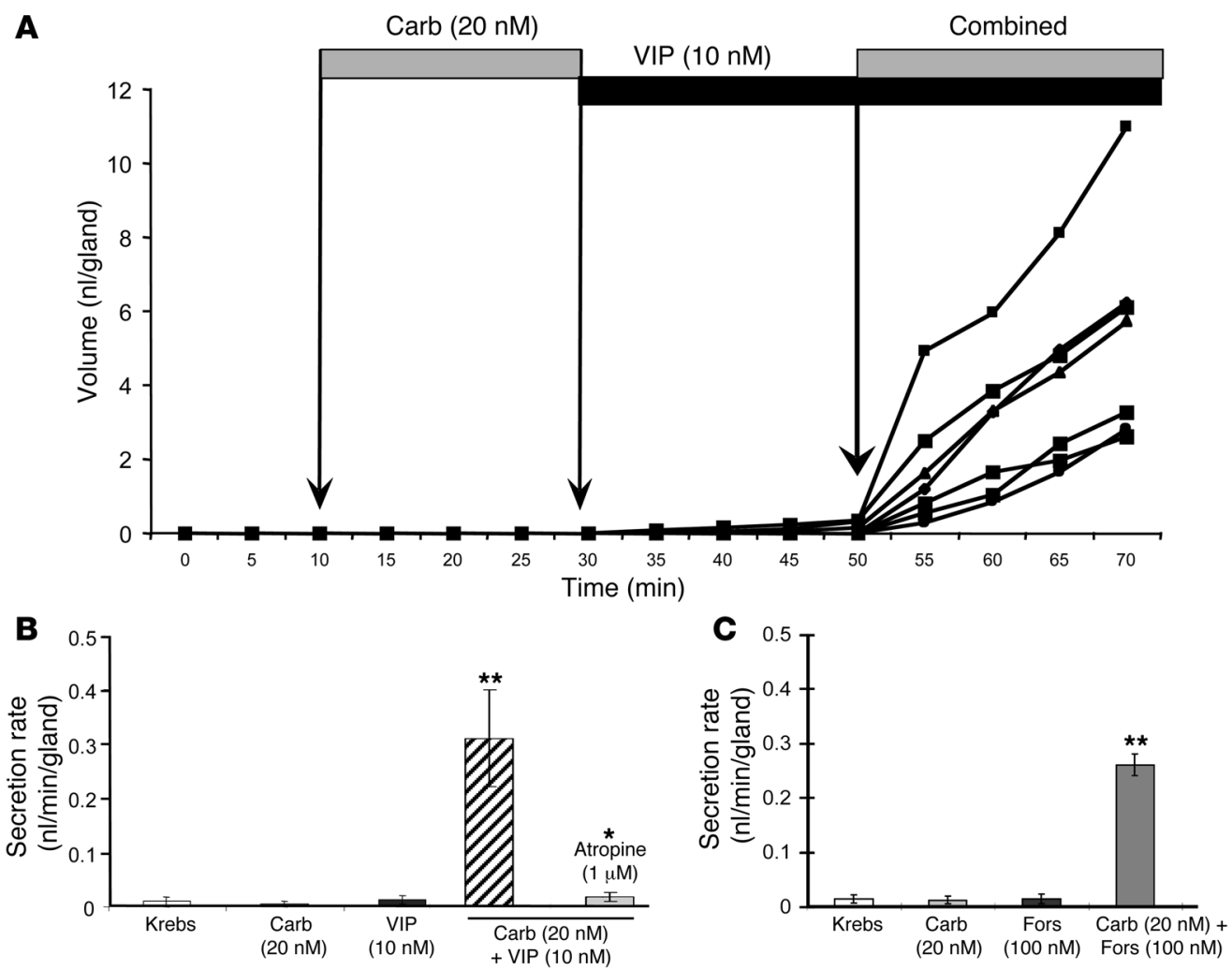

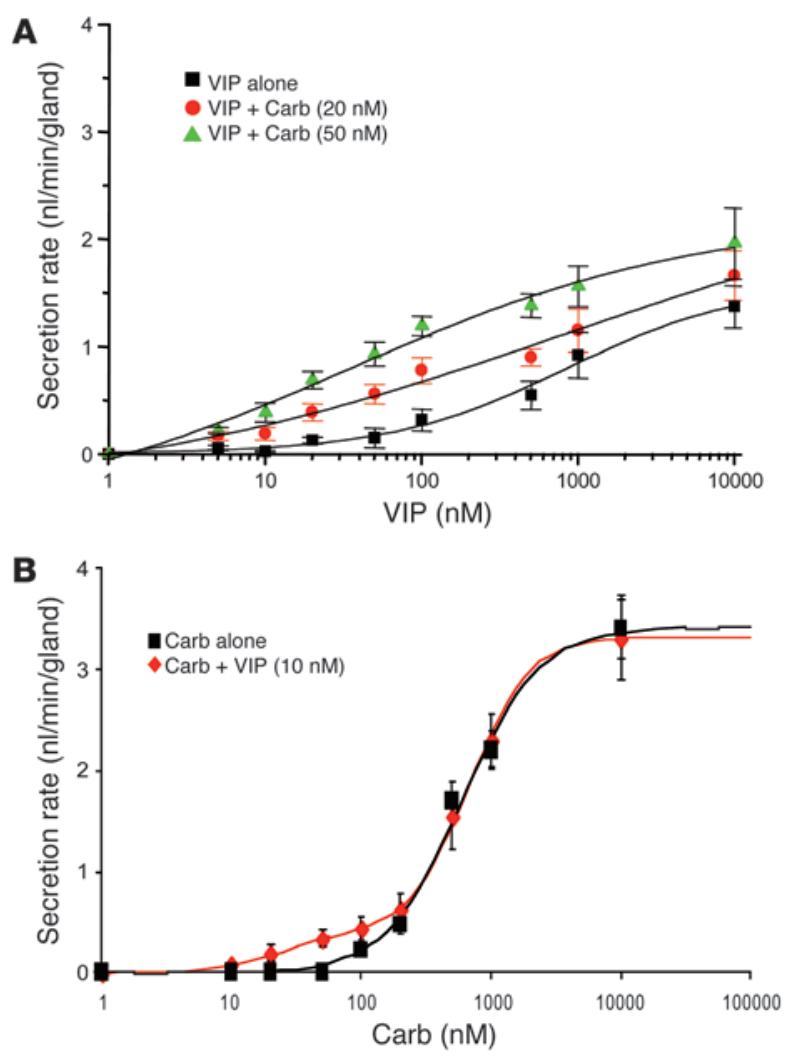

inset), presumably because another apical $\mathrm{Cl}^{-}$channel is activated. Therefore, we stimulated tissues with a 5 -fold greater concentration of carbachol $(100 \mathrm{nM})$ in the absence of VIP - this level of carbachol produced a rate of mucus secretion similar to that produced by $20 \mathrm{nM}$ carbachol plus $10 \mathrm{nM}$ VIP $(0.22 \pm 0.02 \mathrm{nl} / \mathrm{min} /$ gland) - and tested again with the same inhibitors (Figure 6B). Glands that secreted mucus in response to $100 \mathrm{nM}$ carbachol alone here showed a different pattern of inhibition: niflumic acid and CFTR $_{\text {inh }}-172$ each significantly inhibited the response by similar amounts. Inhibition by niflumic acid is consistent with activation of another anion channel, but inhibition by CFTR $_{\text {inh }}-172$ was unexpected. This indicates that CFTR is partially active in these

\section{Figure 6}

Analysis of synergy in pig airway glands. (A) Synergy depended on CFTR and was not inhibited by niflumic acid (Nifl). The mean response to a 20-minute exposure to $20 \mathrm{nM}$ carbachol plus $10 \mathrm{nM}$ VIP was set to $100 \%$. For inhibitor studies, glands were pretreated with either niflumic acid or CFTR inh -172 for $1-5$ minutes prior to exposure to the combined agonists: CFTR inn -172 , but not niflumic acid, significantly inhibited the response. (B) Mucus secretion in response to suprathreshold carbachol displayed a different pharmacology. In these experiments the secretory response to a 20-minute exposure to $100 \mathrm{nM}$ carbachol was set to $100 \%$; this concentration was selected to produce a rate of mucus secretion similar to that observed with $20 \mathrm{nM}$ carbachol plus $10 \mathrm{nM}$ VIP. To assess the inhibitors, the glands were pretreated as above with either niflumic acid or CFTR inh $^{-172}$ followed by $100 \mathrm{nM}$ carbachol. In contrast with the synergy condition, both niflumic acid and CFTR $_{\text {inh }}-172$ significantly inhibited the response compared with carbachol alone, and the combination of inhibitors was additive. For each condition the number of subjects and number of glands (in parentheses) is shown. ${ }^{*} P<0.05 ;{ }^{* *} P<0.01$.

\section{Figure 5}

Range of agonist concentrations over which synergy was observed in pig tracheal submucosal glands. (A) VIP varied from $1 \mathrm{nM}$ to $10 \mu \mathrm{M}$ with carbachol concentrations of 0,20 , and $50 \mathrm{nM}$. (B) Carbachol varied from $1 \mathrm{nM}$ to $10 \mu \mathrm{M}$ alone and in the presence of $10 \mathrm{nM}$ VIP.

conditions, either because it has some level of basal activity or because it is being activated by this higher level of carbachol. The results to this point indicated that activation of CFTR is required for synergy and suggested that $\mathrm{Ca}^{2+}$-activated chloride channels are minimally involved, because niflumic acid had no detectable effect; the residual mucus secretion in the presence of CFTR $_{\text {inh }}-172$ may be explained by the incomplete inhibition of CFTR seen with this compound in some conditions $(41,42)$.

Role of $\mathrm{Ca}^{2+}$-activated $\mathrm{K}^{+}$channels in synergy. Anion-driven fluid secretion by many epithelia is augmented by cell hyperpolarization, secondary to the activation of $\mathrm{Ca}^{2+}$-activated $\mathrm{K}^{+}$channels (43). Thus, we considered the possibility that at the low levels of agonists used here, VIP activates only (or primarily) CFTR, and carbachol activates only (or primarily) $\mathrm{Ca}^{2+}$-activated $\mathrm{K}^{+}$channels. To inhibit $\mathrm{Ca}^{2+}$-activated $\mathrm{K}^{+}$channels, we applied clotrimazole (44) while stimulating glands with a just-suprathreshold concentration of VIP (100 nM) and a subthreshold concentration of carbachol $(50 \mathrm{nM})$. These concentrations produced marked synergy (see Figure 5), but also provided a level of mucus secretion mediated by VIP alone against which the effects of clotrimazole could be tested. In different experiments, clotrimazole $(25 \mu \mathrm{M})$ was applied either before or after the combination of VIP and carbachol. Clotrimazole abolished synergy whether added after (Figure 7A) or before
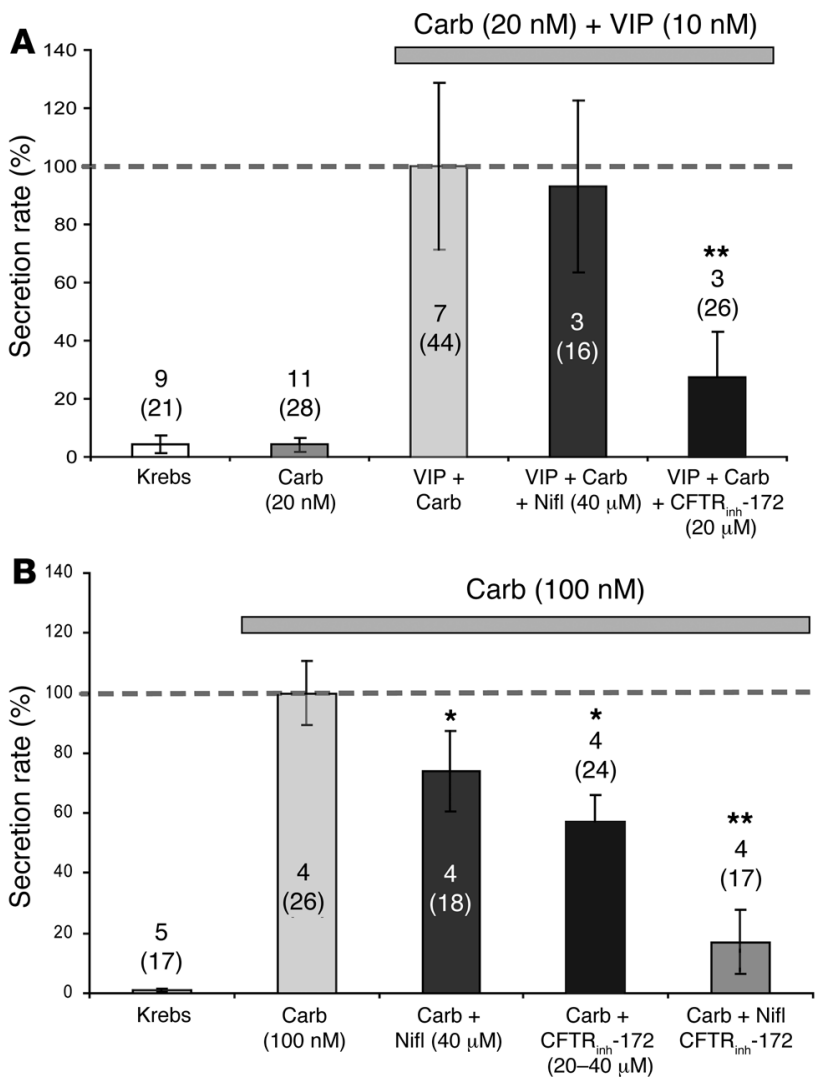

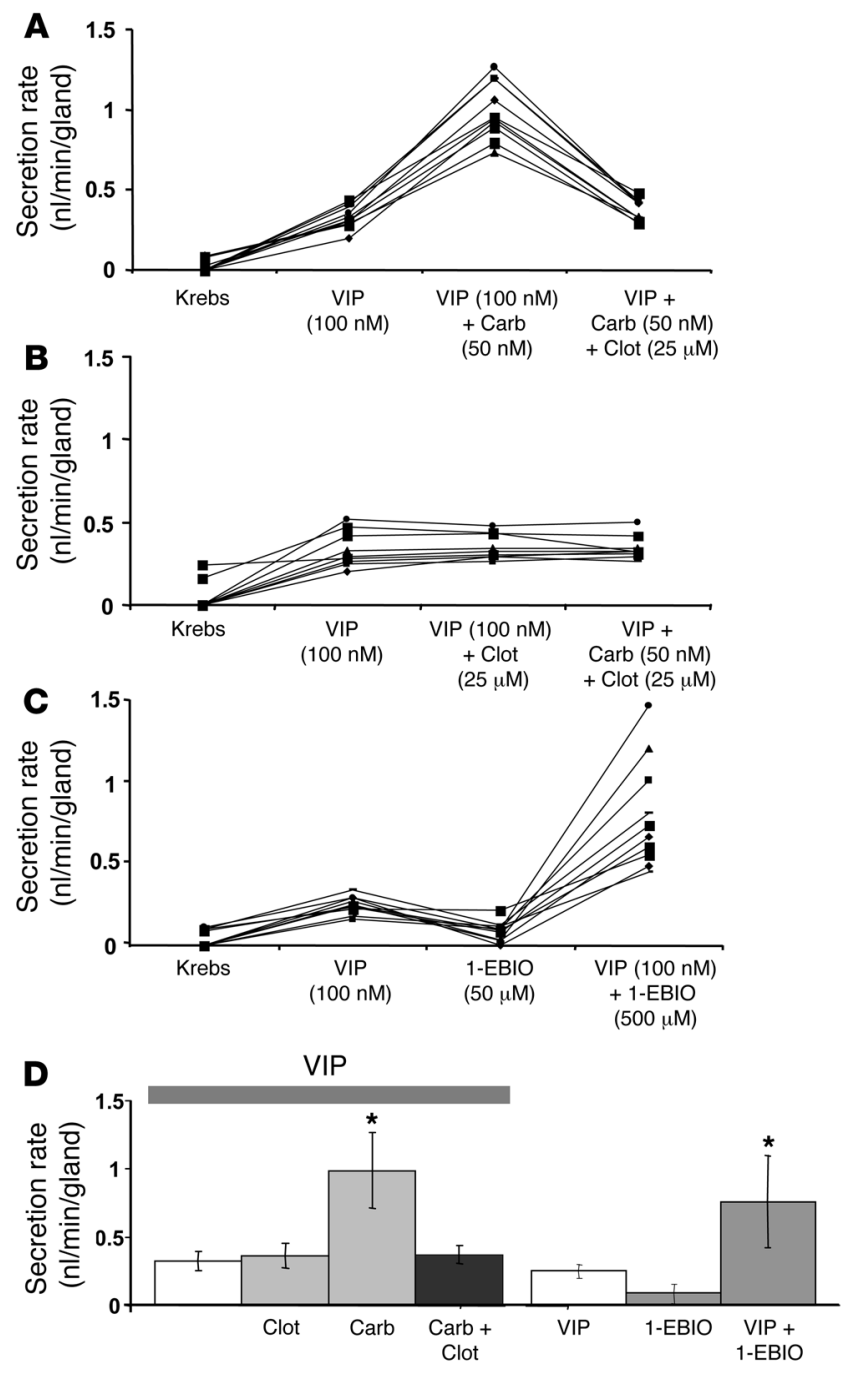

(Figure 7B) the VIP/carbachol combination while not affecting mucus secretion produced by VIP alone. Thus, at these low agonist concentrations, a clotrimazole-sensitive process is rate-limiting for mucus secretion in response to the combined agonists, but not for VIP alone. Figure 7, A and B, show results for individual glands from a single pig; summary data for clotrimazole are shown at the left of Figure 7D, which is based on 23 glands from 3 pigs.

As a further test of the hypothesis that synergy depends upon the separate recruitment of CFTR and $\mathrm{Ca}^{2+}$-activated $\mathrm{K}^{+}$channels, we combined VIP with 1-ethyl-benzimidazolinone (1-EBIO), which is thought to directly activate $\mathrm{Ca}^{2+}$-activated, clotrimazole-sensitive $\mathrm{K}^{+}$channels, as shown in the T-84 colonic crypt cell line (44), the Calu-3 airway gland serous cell line (45), and native intestinal tissues of the mouse (46) and rat (44). We stimulated glands with 100 $\mathrm{nM}$ VIP, $500 \mu \mathrm{M} 1-\mathrm{EBIO}$, or the combination. In pig airway glands, 1-EBIO alone did not stimulate mucus secretion, but when combined with VIP it caused a 3-fold increase in secretion over that seen with VIP alone. Results for 10 glands in a single pig are shown in Figure 7C; summary data from 26 glands in 3 pigs is shown at the right of Figure 7D.

Mucus secretion relies on both $\mathrm{Cl}^{-}$and $\mathrm{HCO}_{3}{ }^{-}$transport. Prior work has shown that pig gland mucus secretion depends on both $\mathrm{Cl}^{-}$ and $\mathrm{HCO}_{3}{ }^{-}$transport, and when one ion transport pathway is

\section{Figure 7}

Synergistic stimulation of mucus secretion from pig airway glands depends upon the recruitment of $\mathrm{Ca}^{2+}$-activated $\mathrm{K}^{+}$channels. (A) The response to $100 \mathrm{nM}$ VIP plus $50 \mathrm{nM}$ carbachol was substantially reduced by $25 \mu \mathrm{M}$ clotrimazole. (B) Clotrimazole did not inhibit the response to VIP alone, but prevented the increase observed with carbachol combined with VIP. (C) 1-EBIO alone $(500 \mu \mathrm{M})$ did not stimulate mucus secretion, but significantly enhanced secretion produced by $100 \mathrm{nM}$ VIP. In A-C, each point represents the mucus secretion rate of a single gland averaged over the preceding 20-minute period of stimulation. Conditions were separated by 1 -minute washes. The connecting lines are visual aids to allow tracking of each gland in the various conditions. (D) Summary data for experiments with clotrimazole (Clot; left, $n=3,23$ glands) and 1-EBIO (right, $n=3,26$ glands). ${ }^{*} P<0.05$.

blocked the other can partially compensate (30-32, 47). In single gland studies using maximal stimulation $(10 \mu \mathrm{M}$ carbachol or $10 \mu \mathrm{M}$ forskolin), mucus secretion was inhibited 50\%-60\% either by bumetanide, which inhibits the $\mathrm{Na}^{+}, \mathrm{K}^{+}, 2 \mathrm{Cl}^{-}$cotransporter (NKCC), or by $\mathrm{HCO}_{3}{ }^{-}$replacement with HEPES, which was used to abrogate $\mathrm{HCO}_{3}{ }^{-}$-mediated fluid secretion. The combination of bumetanide and $\mathrm{HCO}_{3}{ }^{-}$replacement reduced mucus secretion by at least $90 \%$ (14). To determine whether these transporters play the same roles in synergistic secretion, we stimulated pig tracheal glands with $100 \mathrm{nM}$ VIP combined with $50 \mathrm{nM}$ carbachol either in Krebs-Ringer buffer or in the presence of bumetanide, HEPES, or the combination ( $n=2-3,11-22$ glands). As shown in Figure 8, interference with transport of either anion inhibited mucus secretion in response to VIP or VIP plus carbachol by $45 \%-75 \%$, and the combination of bumetanide and HEPES inhibited mucus secretion by approximately $90 \%$. A potentially interesting point is that bumetanide inhibited the synergistic response more effectively (78\%) than did HEPES replacement of $\mathrm{HCO}_{3}{ }^{-}(P<0.02)$. This contrasts with inhibition of responses to saturating levels of VIP, forskolin, or carbachol used individually, which are equally inhibited by HEPES or bumetanide $(14,25)$.

\section{Discussion}

The purpose of these experiments was to test the hypothesis that airway glands secrete significant amounts of mucus in response to low levels of VIP and ACh applied together. We asked this question because ACh and VIP are abundant neurotransmitters used by airway neurons (reviewed in ref. 23) and because of a new hypothesis that routine, "housekeeping" mucus secretion by airway glands is produced by low levels of activity in airway intrinsic neurons, with such secretion constituting an important component of airway mucosal defenses against mundane pathogens (23).

We found that nanomolar concentrations of VIP and carbachol acted synergistically to produce airway gland mucus secretion in both humans and pigs. Such secretion was CFTR dependent, because it was absent in airways from CF subjects and was inhibited in pig airways by CFTR inh -172 . The interaction between VIP and carbachol appeared to occur at the level of gland cells and not neurons, because (a) it was dependent on CFTR; (b) forskolin substituted for VIP; (c) the $\mathrm{K}^{+}$channel opener 1-EBIO substituted for carbachol; and (d) it was inhibited by the $\mathrm{Ca}^{2+}$-activated $\mathrm{K}^{+}$channel inhibitor clotrimazole. However, we cannot entirely exclude effects that might occur if CFTR were also expressed in neurons.

Mechanism of synergy. Models of gland fluid secretion begin with the evidence that secretion was driven by electrogenic $\mathrm{Cl}^{-}, \mathrm{HCO}_{3}{ }^{-}$, 


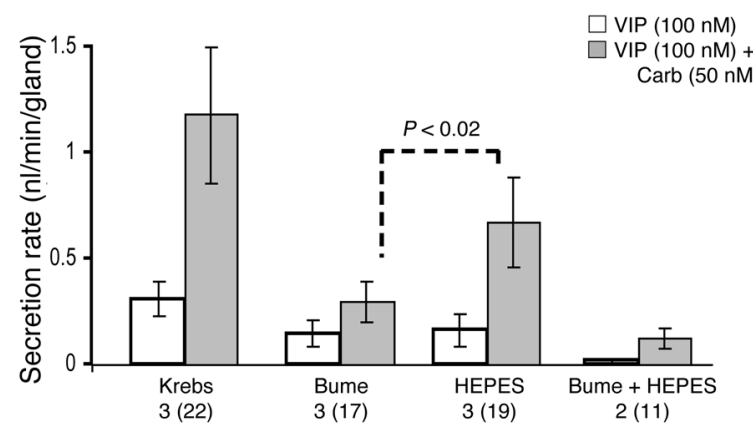

Figure 8

Contribution of $\mathrm{Cl}^{-}$transport (NKCC1) and $\mathrm{HCO}_{3}{ }^{-}$transport to mucus secretion produced by $100 \mathrm{nM}$ VIP or $100 \mathrm{nM}$ VIP plus $50 \mathrm{nM}$ carbachol. The mucus secretion rate prior to stimulation in these experiments was essentially $0(<0.02 \mathrm{nl} / \mathrm{min} / \mathrm{gland})$. VIP-stimulated mucus secretion was equally and significantly $(P<0.05)$ inhibited by the NKCC inhibitor bumetanide or by replacement of $\mathrm{HCO}_{3}{ }^{-}$with $\mathrm{HEPES}$, and the combined treatment eliminated greater than $90 \%$ of mucus secretion. The combined agonists bumetanide and HEPES again caused significant inhibition of mucus secretion that was additive, but in this condition bumetanide was significantly more inhibitory than was HEPES $(P<0.02)$. For each condition the number of subjects and number of glands (in parentheses) is shown.

and $\mathrm{K}^{+}$secretion and was augmented by cellular hyperpolarization. A minimal model of fluid secretion by gland serous cells is shown in Figure 9. This model has much in common with a model developed for sweat secretion $(48,49)$. Our data are consistent with the following points. (a) Low concentrations of ACh activate $\mathrm{K}^{+}$channels but do not activate any apical anion conductances (Figure 9A). (b) Low concentrations of VIP can activate CFTR but apparently have little effect on basolateral $\mathrm{K}^{+}$channels (Figure 9B). Therefore, little or no fluid secretion occurs for these 2 conditions. (c) When combined, the dual activation of basolateral $\mathrm{K}^{+}$channel and apical CFTR supports anion-mediated fluid secretion (Figure 9C). NKCC and other basolateral transporters are active in this condition, but the exact mechanisms for that activation are unclear. (d) Higher levels of $\mathrm{ACh}$ alone recruit $\mathrm{Ca}^{2+}$-activated chloride channels and so produce fluid secretion (Figure 9D). Higher concentrations of VIP

\section{Figure 9}

A minimal gland cell model for synergistic interactions between nanomolar carbachol and VIP on submucosal gland fluid secretion. (A) Low levels of ACh do not produce effective fluid secretion because they activate $\mathrm{K}^{+}$channels $\left(\mathrm{K}_{2}\right)$ but not apical $\mathrm{Cl}^{-}$channels. (B) Low levels of VIP do not produce effective fluid secretion because they activate CFTR but not $\mathrm{K}^{+}$channels. (C) When combined at low levels, ACh (i) activates $\mathrm{Ca}^{2+}$-activated $\mathrm{K}^{+}$channels $\left(\mathrm{K}_{2}\right)$ to increase the driving force through CFTR; it may also increase activity of basolateral transporters. VIP opens CFTR (ii), allowing electrogenic, anion-mediated fluid secretion. (D) At higher levels of ACh, apical $\mathrm{Ca}^{2+}$-activated chloride channels (CaCC) are activated (iii); at higher levels of VIP, cAMP-activated $\mathrm{K}^{+}$channels $\left(\mathrm{K}_{1}\right)$ are activated (iv). Thus, at higher rates of stimulation each pathway alone can produce enough fluid to support mucus secretion. Major unresolved points are the types of gland mucus secretory cells that express $\mathrm{Ca}^{2+}$-activated chloride channels (serous, mucous, or both) and the relative magnitudes of the apical conductances mediated by each type of channel. The apical $\mathrm{K}^{+}$channel is based on single channel recordings in Calu-3 cells (61) and gland cells (J.V. Wu, unpublished observations). alone can recruit basolateral cAMP-dependent $\mathrm{K}^{+}$channels and also support fluid secretion (5). Thus, at higher concentrations of these agonists, or higher rates of neural activity, each agonist alone can support mucus secretion. In this model, gland mucus secretion in response to VIP alone or to VIP in combination with low levels of carbachol depends absolutely on CFTR, whereas mucus secretion in response to higher levels of carbachol is, at least in part, independent of CFTR. Too many uncertainties remain to allow a quantitative model of gland secretion to be formulated and tested.

Differences with prior studies of various glands. Shimura et al. measured glycoconjugate in a study of VIP-carbachol synergism in isolated cat glands (29). The authors concluded that synergy probably resulted from VIP stimulation of muscarinic receptors on neuron terminals because they could not duplicate synergy by substituting db-cAMP for VIP (29). However, we found here that forskolin did substitute for VIP (Figure 4C) and that synergy depended upon CFTR and $\mathrm{Ca}^{2+}$-activated $\mathrm{K}^{+}$channels, supporting a postreceptor process in gland cells as the site of synergy. Sato and Sato (50) studied interactions between methacholine and VIP in monkey palm sweat glands and observed a marked enhancement of cAMP accumulation when methacholine was combined with VIP, but no synergistic effect on the sweat secretion rate. In cat salivary glands, VIP does not itself stimulate secretion, but greatly increases the affinity of agonists to muscarinic receptors (51); this effect was not observed by the same investigators in rat cardiac muscles, indicating tissue specificity for effect (51). These differences indicate that large species and end organ differences can exist in responses to VIP and interactions between VIP and ACh. It is therefore important that we observed VIP/carbachol synergy in airway glands of
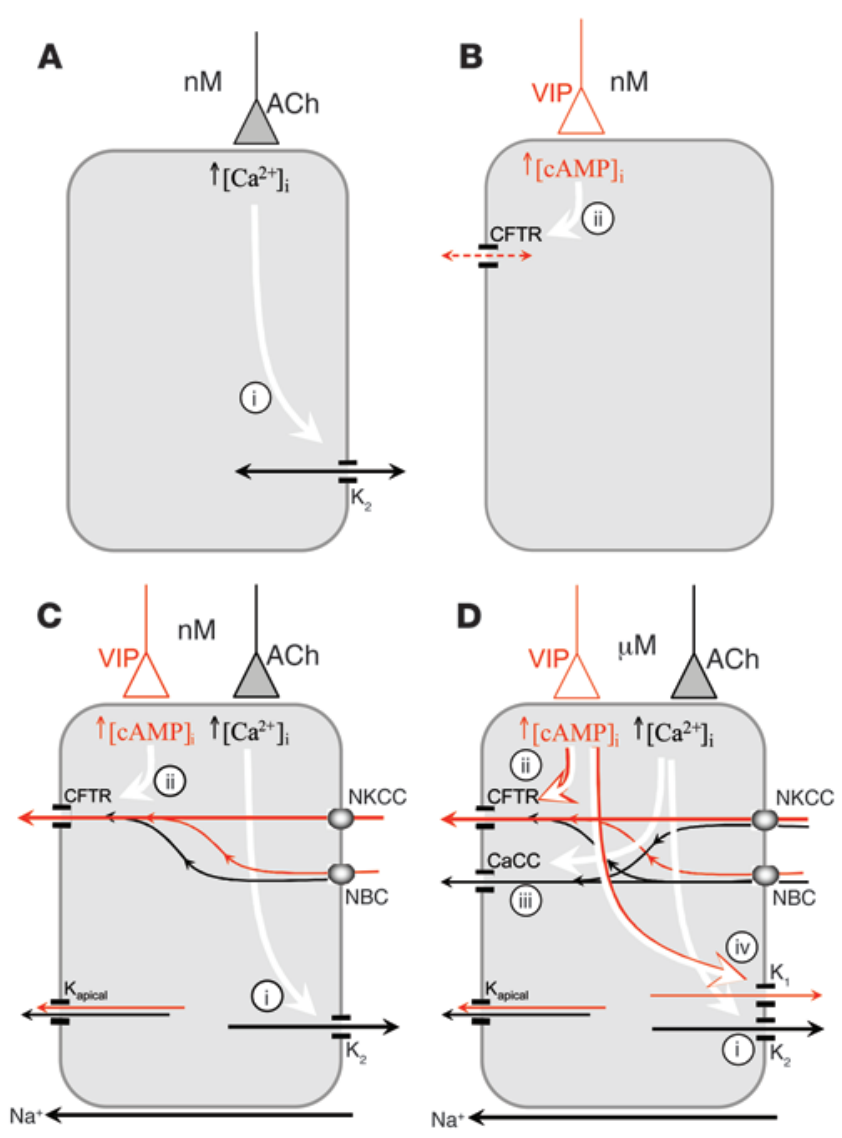
Table 1

Subject characteristics

\begin{tabular}{lccc} 
& Donor & Other disease & CF \\
$n$ & $9^{A}$ & 7 & 7 \\
Male (no. [\%]) & $4(50)$ & $3(43)$ & $3(43)$ \\
Age (mean \pm SD) & $38 \pm 13$ & $57 \pm 9$ & $27 \pm 16$ \\
\hline
\end{tabular}

AAge and sex characteristics were not retrieved for 1 donor trachea.

both humans and pigs. Notably, we have also demonstrated synergy in WT but not $c f t r /-$ mouse tracheal submucosal glands (our unpublished observations).

Functional relevance of low levels of gland mucus secretion. With 50 $\mathrm{nM}$ carbachol plus $50 \mathrm{nM}$ VIP, mucus secretion was about $1 \mathrm{nl} /$ $\mathrm{min} /$ gland (Figure 5). In the trachea, glands are present at a density of approximately 1 per $\mathrm{mm}^{2}$ (52). If the glands were the only source of fluid, and in the absence of other factors, the observed mucus secretion rate would produce a $7-\mu \mathrm{m}$-deep film of surface fluid within about 7 minutes, which is sufficient for mucociliary clearance (53). Much of the fluid secreted into the airways is reabsorbed, raising interesting questions about the fate of macromolecular components of mucus.

Little information is available on levels of neural input to glands, and most studies emphasize vagal control via centrally mediated lung defense reflexes. However, evidence is emerging that networks of airway intrinsic neurons can mediate mucus secretion in the absence of central input (23). For example, transplanted lungs lack central neural input and must rely on the intrinsic nervous system for basal mucus secretion and to respond to mucosal insults (22); mucus clearance continues in transplanted lungs at either a similar $(54)$ or a reduced rate $(55,56)$, and glands in tracheae explanted into nude mice still secrete lysozyme in the absence of any central neural connections; they produce 8.5 -fold more lysozyme than is found in airways without glands (12). Intact central connections provide an additional level of central excitatory vagal tone (24), and no neural inhibition of airway intrinsic neurons is thought to exist (24). The synergy observed between ACh and VIP, both abundantly expressed in airway intrinsic neurons, may be important for basal gland mucus secretion and local responses to mucosal irritants (22), but experiments with intact lungs are required to address these questions.

Relation to CF. Gland mucus secretion is absolutely CFTR dependent when it is mediated by VIP or forskolin alone (5). In the present study, we have shown that it is also CFTR dependent when evoked synergistically by VIP and ACh. It may be relevant that mice lacking VIP have increased airway inflammation (57). It is also interesting that 2 previous studies reported reduced levels of VIP nerves around CF sweat glands (58) and VIP binding sites in CF airways (59). A generalized deficiency in VIP innervation of exocrine organs was once hypothesized to be the basic defect in $\mathrm{CF}$, but we now know that any deficiencies must somehow be secondary to the loss of CFTR. Secondary changes in VIP innervation or receptors cannot explain the loss of CF gland responses we observed, because responses are also lost to forskolin given either alone (5) or as part of a synergy paradigm. Also, isolated CF glands imaged with differential interference contrast optics were still capable of responding to VIP with exocytosis and cell volume changes, although without appreciable bulk mucus flow (our unpublished observations). If combinations of ACh and VIP are important for low-level mucus secretion by airway glands, CF airway glands will secrete less mucus in any conditions that elicit such secretion, which would be expected to result in reduced antimicrobial levels and clearance. In contrast, emergency parasympathetic airway defense reflexes activate glands via strong cholinergic stimulation, and this pathway is, at least in part, spared in CF airways $(5,15,22,26,37-40)$. Treatments that evoke the vagal reflexes (60) may be beneficial for some people with CF.

\section{Methods}

Human airway preparations. Human tracheal and bronchial tissues were obtained following lung transplants and were used within 24 hours. These studies were approved by the Institutional Review Boards of Stanford University, and tissue was only used from patients who had provided written informed consent. Data were obtained from 9 donor tracheae, 7 bronchi from patients with $\mathrm{CF}$, and 7 bronchi from patients who were transplanted for diseases other than CF. Three lungs were from patients who had chronic obstructive pulmonary disease, and the remaining 4 non-CF tissues were from patients with $\alpha 1$-antitrypsin deficiency, interstitial pneumonitis type II autoimmune hepatitis, transposition of greater vessels, and idiopathic pulmonary fibrosis-usual interstitial pneumonia. Results for these 7 subjects did not differ from one another or from the donor trachea, so results from all 16 control subjects were combined for comparison with CF subjects. Subject characteristics are given in Table 1.

Porcine preparations. Pig tracheae were obtained from fresh carcasses of juvenile Yorkshire pigs of either sex weighing 35-50 kg following acute experiments carried out for other purposes. No pigs were sacrificed specifically for the present experiments, nevertheless, the experiments were approved by Stanford University's Institutional Animal Care and Use Committee (IACUC). A total of 34 pig tracheae were used for these experiments.

Human and pig tissues were treated the same after harvesting. They were transported to the laboratory in cold Physiosol solution (Abbott Laboratories) and were then transferred to ice-cold Krebs-Ringer bicarbonate buffer bubbled with $95 \% \mathrm{O}_{2}$ and $5 \% \mathrm{CO}_{2}$, where they were maintained until use. The Krebs-Ringer buffer composition was $115 \mathrm{mM} \mathrm{NaCl}, 2.4 \mathrm{mM} \mathrm{K}_{2} \mathrm{HPO}_{4}$, $0.4 \mathrm{mM} \mathrm{KH}_{2} \mathrm{PO}_{4}, 25 \mathrm{mM} \mathrm{NaHCO}_{3}, 1.2 \mathrm{mM} \mathrm{MgCl}_{2}, 1.2 \mathrm{mM} \mathrm{CaCl}_{2}, 10 \mathrm{mM}$ glucose, and $1.0 \mu \mathrm{M}$ indomethacin. The $\mathrm{pH}$ was 7.4 and osmolarity was adjusted to approximately 290 milliosmoles. A piece of ventral trachea or bronchus of about $0.5 \mathrm{~cm}^{2}$ was pinned mucosal side up, and the mucosa with underlying glands was dissected from the cartilage and mounted in a 35-mm-diameter plastic Petri dish lined with Sylgard (Dow Corning Corp.), with the serosa in the bath $(\sim 1 \mathrm{ml}$ volume $)$ and the mucosa in air. The tissue surface was cleaned and blotted dry with cotton swabs and further dried with a stream of gas, after which 20-30 $\mu$ l of water-saturated mineral oil was placed on the surface. The tissue was warmed to $37^{\circ} \mathrm{C}$ at a rate of about $1.5^{\circ} \mathrm{C} / \mathrm{min}$ and continuously superfused with warmed, humidified $95 \% \mathrm{O}_{2}$ and $5 \% \mathrm{CO}_{2}$. Pharmacological agents were diluted to final concentrations with warmed, gassed bath solution and were added to the serosal side by complete bath replacement.

Optical measurements. Bubbles of mucus within the oil layer were visualized by oblique illumination and digital images were captured with the macro lens of a Nikon digital camera. Each image contained an internal reference grid to compensate for any minor adjustments in magnification made during the experiment. Stored images were analyzed either by direct measurement or with NIH ImageJ software (http://rsb.info.nih. gov/ij/). Mucus volumes were determined from the size of the spherical bubbles; bubbles that were not approximately spherical were omitted from mucus secretion rate analyses. Details of these methods are given in ref. 25 . 
Reagents. Compounds (Sigma-Aldrich) were made fresh or maintained at $-20^{\circ} \mathrm{C}$. Stock solutions of carbachol, VIP, atropine, and bumetanide were dissolved in distilled water; indomethacin was dissolved in ethanol; and

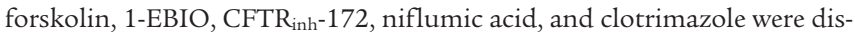
solved in DMSO. All were diluted 1:1,000 with bath solution (except indomethacin, diluted 1:10,000) immediately before use at the concentrations indicated. The highest DMSO concentration in our experiments was $0.2 \%$ and the highest ethanol concentration was $0.01 \%$; we tested $0.5 \%$ DMSO as vehicle alone and found no effect.

Statistics. Data are mean \pm SEM. Unless otherwise indicated, means of different treatment groups were compared with Student's $t$ test for unpaired data. A $P$ value less than 0.05 was considered significant. Curves were fit with Origin software (OriginLab Corp.) using a sigmoid function.

\section{Acknowledgments}

This work was supported by National Institute of Diabetes and Digestive and Kidney Diseases grant RO1-51817 (J.J. Wine), the
Cystic Fibrosis Foundation, and Cystic Fibrosis Research Inc. We thank Hyun Seung Choi of Yonsei University College of Medicine for help with some of the experiments, and Jonathan Philips of the Schering-Plough Research Institute for guiding us to early literature on lung denervation. Tony Nguyen provided technical support, and we are grateful to Jennifer Lyons for discussions. Finally, we are indebted to the Stanford lung transplant team and especially the patients and the families of donors, whose cooperation made this research possible.

Received for publication March 1, 2007, and accepted in revised form June 20, 2007.

Address correspondence to: Jeffrey J. Wine, Cystic Fibrosis Research Laboratory, Room 450, Building 420, Main Quad, Stanford University, Stanford, California 94305-2130, USA. Phone: (650) 725 2462; Fax: (650) 725-5699; E-mail:wine@stanford.edu.
1. Taylor, C.J., Baxter, P.S., Hardcastle, J., and Hardcastle, P.T. 1987. Absence of secretory response in jejunal biopsy samples from children with cystic fibrosis [letter]. Lancet. 2:107-108.

2. Taylor, C.J., Baxter, P.S., Hardcastle, J., and Hardcastle, P.T. 1988. Failure to induce secretion in jejunal biopsies from children with cystic fibrosis. Gut. 29:957-962.

3. Kopelman, H., Durie, P., Gaskin, K., Weizman, Z., and Forstner, G. 1985. Pancreatic fluid secretion and protein hyperconcentration in cystic fibrosis. N. Engl. J. Med. 312:329-334.

4. Kopelman, H., et al. 1988. Impaired chloride secretion, as well as bicarbonate secretion, underlies the fluid secretory defect in the cystic fibrosis pancreas. Gastroenterology. 95:349-355.

5. Joo, N.S., et al. 2002. Absent secretion to vasoactive intestinal peptide in cystic fibrosis airway glands. J. Biol. Chem. 277:50710-50715.

6. Worlitzsch, D., et al. 2002. Effects of reduced mucus oxygen concentration in airway Pseudomonas infections of cystic fibrosis patients. J. Clin. Invest. 109:317-325. doi:10.1172/JCI200213870.

7. Knowles, M.R., and Boucher, R.C. 2002. Mucus clearance as a primary innate defense mechanism for mammalian airways. J. Clin. Invest. 109:571-577. doi:10.1172/JCI200215217.

8. Smith, J.J., Travis, S.M., Greenberg, E.P., and Welsh, M.J. 1996. Cystic fibrosis airway epithelia fail to kill bacteria because of abnormal airway surface fluid. Cell. 85:229-236.

9. Reid, L. 1960. Measurement of the bronchial mucous gland layer: a diagnostic yardstick in chronic bronchitis. Thorax. 15:132-141.

10. Trout, L., Corboz, M.R., and Ballard, S.T. 2001. Mechanism of substance P-induced liquid secretion across bronchial epithelium. Am. J. Physiol. Lung Cell. Mol. Physiol. 281:L639-L645.

11. Wang, X., Zhang, Y., Amberson, A., and Engelhardt, J.F. 2001. New models of the tracheal airway define the glandular contribution to airway surface fluid and electrolyte composition. Am. J. Respir. Cell Mol. Biol. 24:195-202.

12. Dajani, R., et al. 2005. Lysozyme secretion by submucosal glands protects the airway from bacterial infection. Am. J. Respir. Cell Mol. Biol. 32:548-552.

13. Wine, J.J., and Joo, N.S. 2004. Submucosal glands and airway defense. Proc. Am. Thorac. Soc. 1:47-53.

14. Joo, N.S., Saenz, Y., Krouse, M.E., and Wine, J.J. 2002. Mucus secretion from single submucosal glands of pig. Stimulation by carbachol and vasoactive intestinal peptide. J. Biol. Chem. 277:28167-28175.

15. Jayaraman, S., Joo, N.S., Reitz, B., Wine, J.J., and Verkman, A.S. 2001. Submucosal gland secretions in airways from cystic fibrosis patients have nor- mal $[\mathrm{Na}+]$ and $\mathrm{pH}$ but elevated viscosity. Proc. Natl. Acad. Sci. U. S. A. 98:8119-8123.

16. Baker, D.G., McDonald, D.M., Basbaum, C.B., and Mitchell, R.A. 1986. The architecture of nerves and ganglia of the ferret trachea as revealed by acetylcholinesterase histochemistry. J. Comp. Neurol. 246:513-526.

17. Dey, R.D., Satterfield, B., and Altemus, J.B. 1999. Innervation of tracheal epithelium and smooth muscle by neurons in airway ganglia. Anat. Rec. 254:166-172.

18. Zhu, W., and Dey, R.D. 2001. Projections and pathways of VIP- and nNOS-containing airway neurons in ferret trachea. Am. J. Respir. Cell Mol. Biol. 24:38-43.

19. Dey, R.D., Shannon, W.A., Jr., and Said, S.I. 1981. Localization of VIP-immunoreactive nerves in airways and pulmonary vessels of dogs, cat, and human subjects. Cell Tissue Res. 220:231-238.

20. Fischer, A., and Hoffmann, B. 1996. Nitric oxide synthase in neurons and nerve fibers of lower airways and in vagal sensory ganglia of man. Correlation with neuropeptides. Am. J. Respir. Crit. Care Med. 154:209-216.

21. Fischer, A., Canning, B.J., and Kummer, W. 1996. Correlation of vasoactive intestinal peptide and nitric oxide synthase with choline acetyltransferase in the airway innervation. Ann. N. Y. Acad. Sci. 805:717-722.

22. Ianowski, J.P., Choi, J.Y., Wine, J.J., and Hanrahan, J.W. 2007. Mucus secretion by single tracheal submucosal glands from normal and cystic fibrosis transmembrane conductance regulator CFTR knock-out mice. J. Physiol. 580:301-314.

23. Wine, J.J. 2007. Parasympathetic control of airway submucosal glands: central reflexes and the airway intrinsic nervous system. Auton. Neurosci. 133:35-54.

24. Mitchell, R.A., Herbert, D.A., Baker, D.G., and Basbaum, C.B. 1987. In vivo activity of tracheal parasympathetic ganglion cells innervating tracheal smooth muscle. Brain Res. 437:157-160.

25. Joo, N.S., Wu, J.V., Krouse, M.E., Saenz, Y., and Wine, J.J. 2001. Optical method for quantifying rates of mucus secretion from single submucosal glands. Am. J. Physiol. Lung Cell. Mol. Physiol. 281:L458-L468.

26. Joo, N.S., and Wine, J.J. 2006. Role of CFTR in cholinergically stimulated airway gland mucus secretion. Pediatr. Pulmonol. Suppl. 29:245.

27. Choi, J.Y., Joo, N.S., Wu, J.V., Krouse, M.E., and Wine, J.J. 2006. Submucosal gland secretion in pig airways: synergistic stimulation by low levels of VIP and carbachol. Pediatr. Pulmonol. Suppl. 29:238.

28. Choi, J.Y., Joo, N.S., Wu, J.V., Krouse, M.E., and Wine, J.J. 2006. Human submucosal gland secretion: synergic stimulation by low levels of VIP and carbachol is lost in cystic fibrosis. Pediatr. Pulmonol. Suppl. 29:238.

29. Shimura, S., Sasaki, T., Ikeda, K., Sasaki, H., and Takishima, T. 1988. VIP augments cholinergicinduced glycoconjugate secretion in tracheal submucosal glands. J. Appl. Physiol. 65:2537-2544.

30. Inglis, S.K., Corboz, M.R., Taylor, A.E., and Ballard, S.T. 1997. Effect of anion transport inhibition on mucus secretion by airway submucosal glands. Am. J. Physiol. 272:L372-L377.

31. Inglis, S.K., Corboz, M.R., and Ballard, S.T. 1998. Effect of anion secretion inhibitors on mucin content of airway submucosal gland ducts. Am.J. Physiol. 274:L762-L766.

32. Trout, L., Gatzy, J.T., and Ballard, S.T. 1998. Acetylcholine-induced liquid secretion by bronchial epithelium: role of Cl- and $\mathrm{HCO} 3$ - transport. Am. J. Physiol. 275:L1095-L1099.

33. Trout, L., King, M., Feng, W., Inglis, S.K., and Ballard, S.T. 1998. Inhibition of airway liquid secretion and its effect on the physical properties of airway mucus. Am. J. Physiol. 274:L258-L263.

34. Trout, L., Townsley, M.I., Bowden, A.L., and Ballard, S.T. 2003. Disruptive effects of anion secretion inhibitors on airway mucus morphology in isolated perfused pig lung. J. Physiol. 549:845-853.

35. Griffin, A., Newman, T.M., and Scott, R.H. 1996. Electrophysiological and ultrastructural events evoked by methacholine and intracellular photolysis of caged compounds in cultured ovine trachea submucosal gland cells. Exp. Physiol. 81:27-43.

36. Ma, T., et al. 2002. Thiazolidinone CFTR inhibitor identified by high-throughput screening blocks cholera toxin-induced intestinal fluid secretion. J. Clin. Invest. 110:1651-1658. doi:10.1172/JCI200216112.

37. Joo, N.S., Irokawa, T., Robbins, R.C., Whyte, R.I., Wine, J.J. 2003. Defective acetylcholine-stimulated mucus secretion from cystic fibrosis airway submucosal glands. Pediatr. Pulmonol. Suppl. 25:208.

38. Thiagarajah, J.R., Song, Y., Haggie, P.M., and Verkman, A.S. 2004. A small molecule CFTR inhibitor produces cystic fibrosis-like submucosal gland fluid secretions in normal airways. FASEB J. 18:875-877.

39. Song, Y., Salinas, D., Nielson, D.W., and Verkman, A.S. 2006. Hyperacidity of secreted fluid from submucosal glands in early cystic fibrosis. Am. J. Physiol. Cell Physiol. 290:C741-C749.

40. Knowles, M.R., et al. 1997. Ion composition of airway surface liquid of patients with cystic fibrosis as compared with normal and disease-control subjects [erratum 1998, 101:285]. J. Clin. Invest. 100:2588-2595.

41. Li, H., Findlay, I.A., and Sheppard, D.N. 2004. The relationship between cell proliferation, $\mathrm{Cl}^{-}$secretion, and renal cyst growth: a study using CFTR 
inhibitors. Kidney Int. 66:1926-1938

42. Wang, X.F., Reddy, M.M., and Quinton, P.M. 2004. Effects of a new cystic fibrosis transmembrane conductance regulator inhibitor on $\mathrm{Cl}^{-}$conductance in human sweat ducts. Exp. Physiol. 89:417-425.

43. Petersen, O.H., and Maruyama, Y. 1984. Calciumactivated potassium channels and their role in secretion. Nature. 307:693-696.

44. Devor, D.C., Singh, A.K., Gerlach, A.C., Frizzell, R.A., and Bridges, R.J. 1997. Inhibition of intestinal Cl- secretion by clotrimazole: direct effect on basolateral membrane $\mathrm{K}+$ channels. Am. J. Physiol. 273:C531-C540.

45. Devor, D.C., et al. 1999. Bicarbonate and chloride secretion in Calu-3 human airway epithelial cells. J. Gen. Physiol. 113:743-760.

46. Hamilton, K.L., Meads, L., and Butt, A.G. 1999. 1-EBIO stimulates Cl- secretion by activating a basolateral $\mathrm{K}+$ channel in the mouse jejunum. Pflugers Arch. 439:158-166.

47. Ballard, S.T., Trout, L., Garrison, J., and Inglis, S.K. 2006. Ionic mechanism of forskolin-induced liquid secretion by porcine bronchi. Am. J. Physiol. Lung Cell. Mol. Physiol. 290:L97-L104.

48. Reddy, M.M., Bell, C.L., and Quinton, P.M. 1997.
Cystic fibrosis affects specific cell type in sweat gland secretory coil. Am. J. Physiol. 273:C426-C433.

49. Reddy, M.M., and Bell, C.L. 1996. Distinct cellular mechanisms of cholinergic and beta-adrenergic sweat secretion. Am. J. Physiol. 271:C486-C494.

50. Sato, K., and Sato, F. 1987. Effect of VIP on sweat secretion and CAMP accumulation in isolated simian eccrine glands. Am. J. Physiol. 253:R935-R941.

51. Lundberg, J.M., Hedlund, B., and Bartfai, T. 1982. Vasoactive intestinal polypeptide enhances muscarinic ligand binding in cat submandibular salivary gland. Nature. 295:147-149.

52. Tos, M. 1966. Development of the tracheal glands in man. Number, density, structure, shape, and distribution of mucous glands elucidated by quantitative studies of whole mounts. Acta Pathol. Microbiol. Scand. 68:1-130.

53. Matsui, H., et al. 1998. Evidence for periciliary liquid layer depletion, not abnormal ion composition, in the pathogenesis of cystic fibrosis airways disease. Cell. 95:1005-1015.

54. Brody, J.S., et al. 1972. Mucociliary clearance after lung denervation and bronchial transection. J. Appl. Physiol. 32:160-164.

55. Edmunds, L.H., Jr., Graf, P.D., Sagel, S.S., and
Greenspan, R.H. 1970. Radiographic observations of clearance of tantalum and barium sulfate particles from airways. Invest. Radiol. 5:131-141.

56. Edmunds, L.H., Jr., Stallone, R.J., Graf, P.D., Sagel, S.S., and Greenspan, R.H. 1969. Mucus transport in transplanted lungs of dogs. Surgery. 66:15-22.

57. Szema, A.M., et al. 2006. Mice lacking the VIP gene show airway hyperresponsiveness and airway inflammation, partially reversible by VIP. Am. J. Physiol. Lung Cell. Mol. Physiol. 291:L880-L886.

58. Heinz-Erian, P., Dey, R.D., Flux, M., and Said, S.I. 1985. Deficient vasoactive intestinal peptide innervation in the sweat glands of cystic fibrosis patients. Science. 229:1407-1408.

59. Sharma, R.K., Addis, B.J., and Jeffery, P.K. 1995. The distribution and density of airway vasoactive intestinal polypeptide (VIP) binding sites in cystic fibrosis and asthma. Pulm. Pharmacol. 8:91-96.

60. Elkins, M.R., et al. 2006. A controlled trial of longterm inhaled hypertonic saline in patients with cystic fibrosis. N. Engl. J. Med. 354:229-240.

61. Wu, J.V., Krouse, M.E., Rustagi, A., Joo, N.S., and Wine, J.J. 2004. An inwardly rectifying potassium channel in apical membrane of Calu-3 cells. J. Biol. Chem. 279:46558-46565. 